\title{
Protein engineering of conger eel galectins by tracing of molecular evolution using probable ancestral mutants
}

\author{
Ayumu Konno', Shintarou Yonemaru', Atsushi Kitagawa², Koji Muramoto' ${ }^{1}$ Tsuyoshi Shirai ${ }^{2}$, Tomohisa Ogawa ${ }^{1 *}$
}

\begin{abstract}
Background: Conger eel galectins, congerin I (Conl) and congerin II (Conll), show the different molecular characteristics resulting from accelerating evolution. We recently reconstructed a probable ancestral form of congerins, Con-anc. It showed properties similar to those of Conll in terms of thermostability and carbohydrate recognition specificity, although it shares a higher sequence similarity with Conl than Conll.

Results: In this study, we have focused on the different amino acid residues between Con-anc and Conl, and have performed the protein engineering of Con-anc through site-directed mutagenesis, followed by the molecular evolution analysis of the mutants. This approach revealed the functional importance of loop structures of congerins: (1) $\mathrm{N}$ - and C-terminal and loop 5 regions that are involved in conferring a high thermostability to Conl; (2) loops 3, 5, and 6 that are responsible for stronger binding of Conl to most sugars; and (3) loops 5 and 6, and Thr38 residue in loop 3 contribute the specificity of Conl toward lacto- $N$-fucopentaose-containing sugars.

Conclusions: Thus, this methodology, with tracing of the molecular evolution using ancestral mutants, is a powerful tool for the analysis of not only the molecular evolutionary process, but also the structural elements of a protein responsible for its various functions.
\end{abstract}

\section{Background}

Molecular evolution refers to the evolutionary process at the macromolecular level, such as at the DNA, RNA, and protein levels. It encompasses the reconstruction of the evolutionary history of organisms and macromolecules (i.e., molecular phylogeny) on the basis of the sequence data of nucleic acids and proteins. The primary event in molecular evolution is a mutational change in genes that may be caused by the substitution or insertion/deletion of a nucleotide, recombination, etc.; otherwise, in general, DNA sequences are copied exactly during the process of chromosome replication. Subsequently, they spread in a population by genetic drift and/or natural selection, and eventually get established in a species $[1,2]$. Thus, the evolutionary history over a period of multibillion years has its basis in the DNA. To understand the molecular evolution of proteins in nature, we usually refer to the relationships and

\footnotetext{
* Correspondence: ogawa@biochem.tohoku.ac.jp

'Department of Biomolecular Science, Graduate School of Life Sciences, Tohoku University, Sendai 981-8555, Japan
}

rates of changes in the sequence data inferred from proteins identified so far. More recent advances in bioinformatics and structural biology, besides recombinant protein expression techniques, have enabled us to analyze the molecular evolution of proteins more directly, explore the evolutionary strategies of natural proteins, and generate novel tailor-made proteins.

Galectins are defined as proteins having at least one characteristic carbohydrate-recognition domain with $\mathrm{Ca}^{2}$ ${ }^{+}$-independent affinity for $\beta$-galactoside, and they share certain conserved sequence elements [3]. To date, 15 galectins have been identified in mammals. They are involved in many biological phenomena, including cell adhesion, differentiation, morphogenesis, innate immunity, apoptosis, and metastasis of malignant cells [4-8]. Furthermore, the members of the galectin family have been isolated from a large variety of metazoan phyla, from invertebrates such as nematodes, insects, and sponges to vertebrates such as fish and chicken, as well as mammals $[9,10]$. On the basis of their structures, 
galectins are classified into three types: proto-, chimera-, and tandem repeat-type galectins [11].

Conger eel (Conger myriaster) contains two proto-type galectins, namely, congerin I (ConI) and congerin II (ConII) in the skin mucus [12,13]. ConI and ConII consist of 136 and 135 amino acid residues, respectively, and both contain acetylated N-termini $[13,14]$. However, they have no cysteine residue that is related to oxidizing inactivation found in some galectins of higher vertebrates. Congerins are considered to participate in the host defense against infectious agents, such as bacteria and parasites. For example, ConI and ConII mainly exist in the frontier organs and tissues that delineate the body from the outer environment, such as the epidermal club cells of the skin, wall of the oral cavity, pharynx, esophagus, and gills; in addition, they also exhibit agglutination activity against the marine pathogen, Vibrio anguillarum $[12,15,16]$. Moreover, it was recently reported that congerins can exert opsonic effects and can reach the intestinal lumen without enzymatic digestion $[17,18]$.

The molecular evolutionary and X-ray crystallography analyses of ConI and ConII revealed that they have evolved in an accelerating manner, resulting in the emergence of new structures, including the strand-swap structure and a unique carbohydrate-binding site; this in turn resulted in a unique carbohydrate-binding ability [15,19-22]. We recently reconstructed a probable ancestral form of congerin (Con-anc) and found that it showed properties similar to those of ConII in terms of thermostability and carbohydrate-recognition specificity, except for $\alpha 2,3$-sialyl galactose, although Con-anc was observed to share a higher sequence similarity with ConI than ConII [23]. This indicates that only the 31 different amino acid residues between ConI and Conanc are involved in conferring the characteristics of ConI, which are acquired during its adaptive molecular evolution from Con-anc. To identify the determinants of selection pressures in the evolutionary process and the structural elements associated with the unique carbohydrate-binding activities of ConI, in the present study, we focused on the different amino acid residues between Con-anc and ConI, and conducted a dissection analysis using the chimera mutants of Con-anc and ConI, tracing its evolutionary history to ConI.

\section{Results and Discussion}

Design and preparation of the chimeric mutants of Conanc and Conl

As the $\mathrm{N}$ - and $\mathrm{C}$-terminal regions located at the intersubunit interface of the congerins and L5 region involved in the formation of the lactose-binding site are different for ConI and Con-anc (Figure 1A), first, the $\mathrm{N}$-and $\mathrm{C}$-termini and the $\mathrm{L} 5$ regions of Con-anc were mutagenized. Thus, the following 3 Con-anc mutants were prepared: (1) Con-anc-N/C, in which the N- and $\mathrm{C}$-termini were substituted with the corresponding residues of ConI; (2) Con-anc-L5, in which the L5 region was substituted with the corresponding sequence of ConI; and (3) Con-anc-N/C/L5, which had mutations of both Con-anc-N/C and Con-anc-L5 (Figure 1B). As the binding ability of Con-anc-N/C/L5 was only $30 \%-40 \%$ of that of ConI (described later), the other structural elements responsible for the strong binding activity of ConI, namely, L6 and L3 (Thr38), located at the carbohydrate-binding cleft, were also investigated (Figure 1A). Thus, the Con-anc mutants, in which the L6 and L3 regions were substituted with the corresponding sequences of ConI, i.e., Con-anc-N/C/L5/L6, Con-ancN/C/L5/L3, and Con-anc-N/C/L5/L6/L3 (Figure 1B), were prepared, and their carbohydrate-binding activities were determined by frontal affinity chromatography (FAC). To analyze the molecular evolutionary relationship among the ancestral mutants and ConI, the phylogenetic tree including the chimera mutants between Con-anc and ConI was constructed (Figure 2). The tree branched out from the node of each mutant with zero distance, suggesting that the chimera mutants are hypothetical ancestral mutants of ConI on molecular evolution.

\section{Thermostability of Con-anc and mutants}

Figure 3 shows the thermostabilities of ConI, ConII, and Con-anc and its mutants. Interestingly, all mutants, i.e., Con-anc-N/C, Con-anc-L5, and Con-anc-N/C/L5, possessed higher thermostabilities than Con-anc; Conanc-N/C/L5, in particular, showed a high stability, comparable with that of ConI. The half-activity retention temperature $\left(\mathrm{T}_{\mathrm{m}}\right)$-the temperature at which $50 \%$ hemagglutination activity was retained after $30 \mathrm{~min}$ of incubation-of Con-anc and ConII were 44 and $46^{\circ} \mathrm{C}$, respectively. On the other hand, Con-anc-N/C and Conanc-L5 showed a $\sim 2^{\circ} \mathrm{C}$ higher $\mathrm{T}_{\mathrm{m}}$ value $\left(48^{\circ} \mathrm{C}\right)$ than that of Con-anc, and Con-anc-N/C/L5 showed a $6^{\circ} \mathrm{C}$ higher $\mathrm{T}_{\mathrm{m}}$ value $\left(52^{\circ} \mathrm{C}\right)$ than that of Con-anc, but were comparable with that of ConI. These results indicate that the $\mathrm{N}$ - and C-terminal regions along with the L5 region of ConI are involved in conferring high thermostability, although the $\mathrm{N}$ - and $\mathrm{C}$-terminal regions are located at the inter-subunit interface and are involved in the strand-swap structure of ConI. Substitutions of amino acid residues at the $\mathrm{N}$ - and $\mathrm{C}$-termini, namely, $\mathrm{E} 5 \mathrm{Q}$, K12T, A118F, N120P, and F132L, may stabilize the strand-swap structure, making it comparable with that of ConI. The strand swapping (or domain swapping) is a motivity of quaternary structure formation in protein evolution; a protein becomes multimeric by donating a part ( $\beta$ strand) of the molecule to a cognate molecule 
$\mathbf{A}$

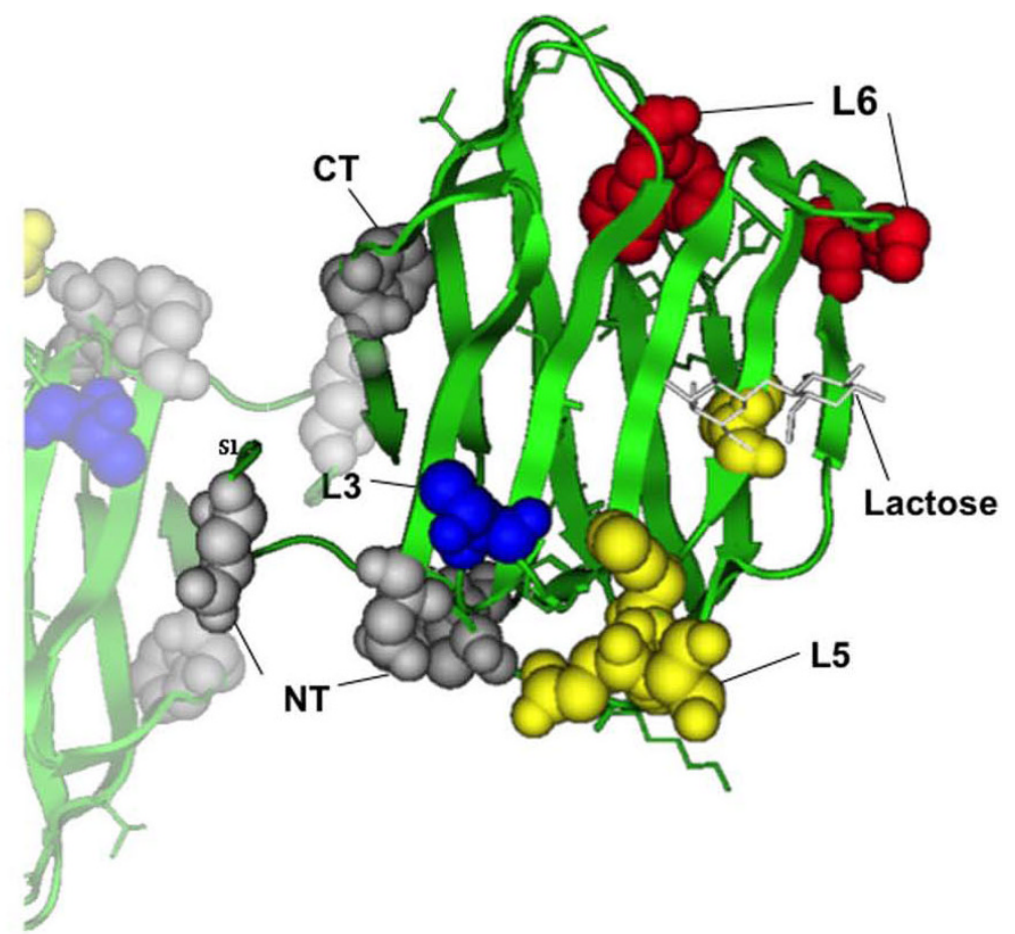

B

Con-anc

Con-anc-N/C

Con-anc-L5
Con-anc-N/C/L

Con-anc-N/C/L 5/L6

Con-anc-N/C/L5/L3

Con-anc-N/C/L $5 / \mathrm{L} 6 / \mathrm{L} 3$

ConI

ConII

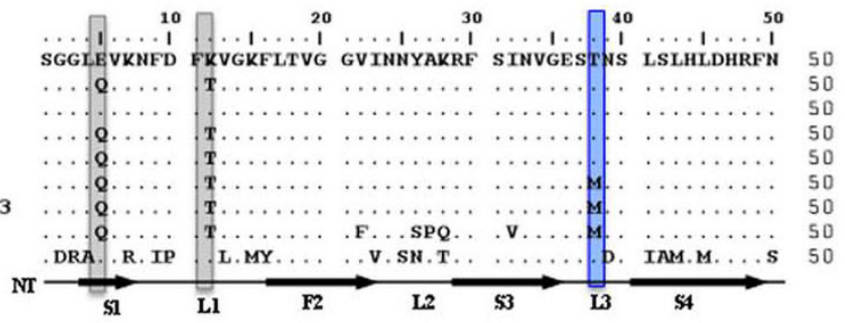

Con-anc

Con-anc-N/C

Con-anc- $\mathrm{L} 5$

Con-anc-N/C/L 5

Con-anc-N/C/L 5/L6

Con-anc-N/C/L $5 / L 3$

Con-anc-N/C/L5/L6/L3

ConI

ConII

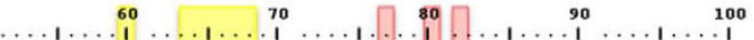
YGADQNTIVL NSMVN--SGW ETEQRSKNFP FSAGEYFEIT ITFDTNKFYI 98
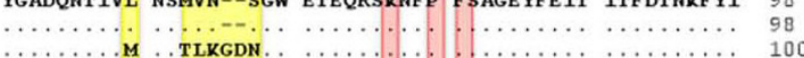

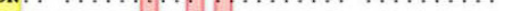

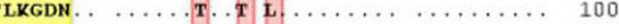
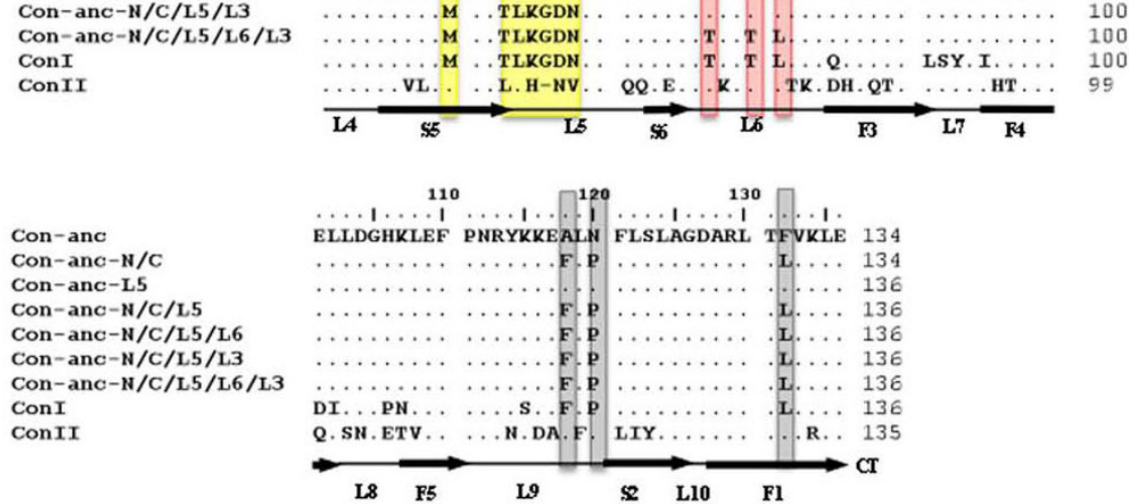

Figure 1 Structure and mutants of Con-anc. (A) 3D structure of Con-anc with liganded lactose, which was predicted by homology modeling, based on congerin I. The amino acid residues in $N$ - and C-termini (NT and $C T$, respectively) and loops 3, 5, and 6 ( $L 3, L 5$, and $L 6$, respectively) of Con-anc mutants are represented by the space-filling model. (B) Aligned amino acid sequences of Conl, Conll, Con-anc, and Con-anc mutants. The sequences were aligned using the ClustalW program. Residue numbers of Conl were used as reference for all the congerins and mutants in this study. Positions of the strands (S1-S6, F1-F5) and loops (L1-L10) are indicated by thick and thin horizontal lines, respectively. The mutated amino acid positions are boxed in color. 


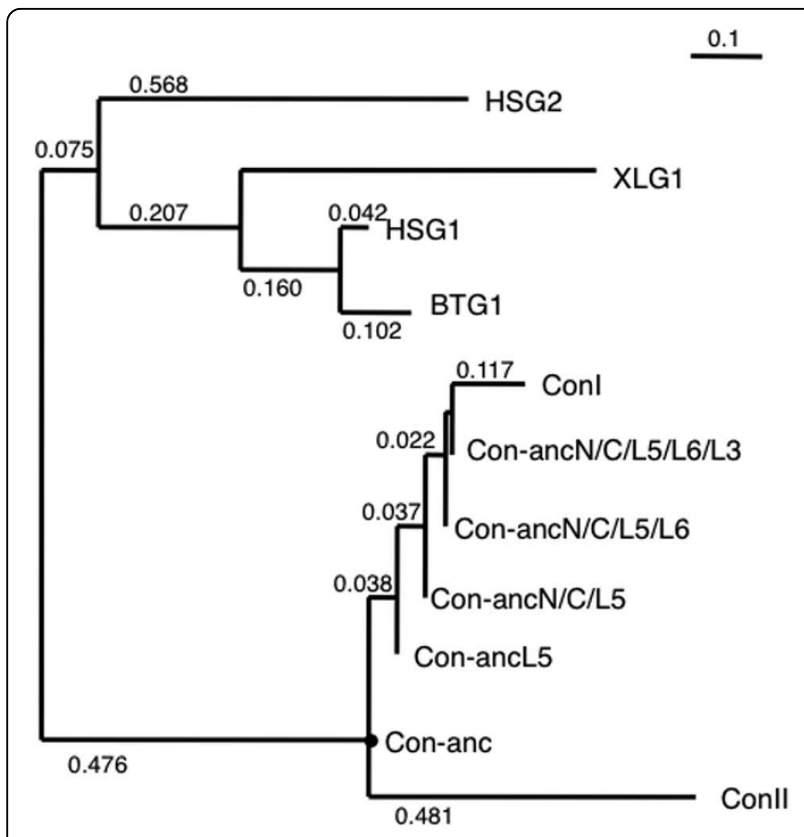

Figure 2 The molecular phylogenetic tree of galectins including Con-anc and mutants. The phylogenetic tree was inferred from the amino acid sequences.

and then accepting the corresponding portion from the cognate. The strand-swap in ConI is a variation of domain swapping, because the conformation of the swapped strands is changed from anti-parallel (in Con II) to parallel (in Con I). The strand-swap structure in ConI increases the inter-subunit contact surface area and the number of inter-subunit hydrogen bonds, resulting the enhancement of its dimeric stability and its cross-linking activity [19]. Thus, the $\mathrm{N}$ - and C-terminal regions contribute to the dimeric stability associated with the hemagglutinating activity, although it is not clear whether Con-anc adopts the strand-swap conformation or not. Meanwhile, substitution of the L5 region of Con-anc with the corresponding sequence of ConI conferred a more hydrophilic property to L5, as demonstrated by the hydropathy values of the L5 regions of Con-anc (LNSMVNS) and ConI (MNSTLKGDN), which were estimated to be 1.3 and -10.6, respectively [24]. In general, the hydrophilic residues on the surface of proteins are believed to increase thermostability [25-27].

Carbohydrate-binding properties of Con-anc and mutants The carbohydrate-binding specificities and activities of ConI, ConII, and Con-anc and its mutants, namely, Conanc-N/C, Con-anc-L5, Con-anc-N/C/L5, Con-anc-N/C/ L5/L6, Con-anc-N/C/L5/L3, and Con-anc-N/C/L5/L6/L3, all of which were determined by FAC, are summarized in Table 1. In the previous report [23], we demonstrated that the sugar-binding specificity of Con-anc-L5 was similar to that of ConII, except for the specific oligosaccharides including lacto- $N$-biosyl (Galß1-3GlcNAc) or lacto- $N$-neobiosyl (Gal $\beta 1-4 G l c N A c)$ moieties, especially, lacto- $N$-fucopentaose-II (LNFP-II, Lewis a $\left.\left(\mathrm{Le}^{\mathrm{a}}\right)\right)(\# 44)$, lacto- $N$-difucohexaose (LNDFH, Le ${ }^{\text {b }}$ (\#46), and A-heptasaccharide (\#48). However, in the present work, we have demonstrated increased carbohydrate-binding activity of

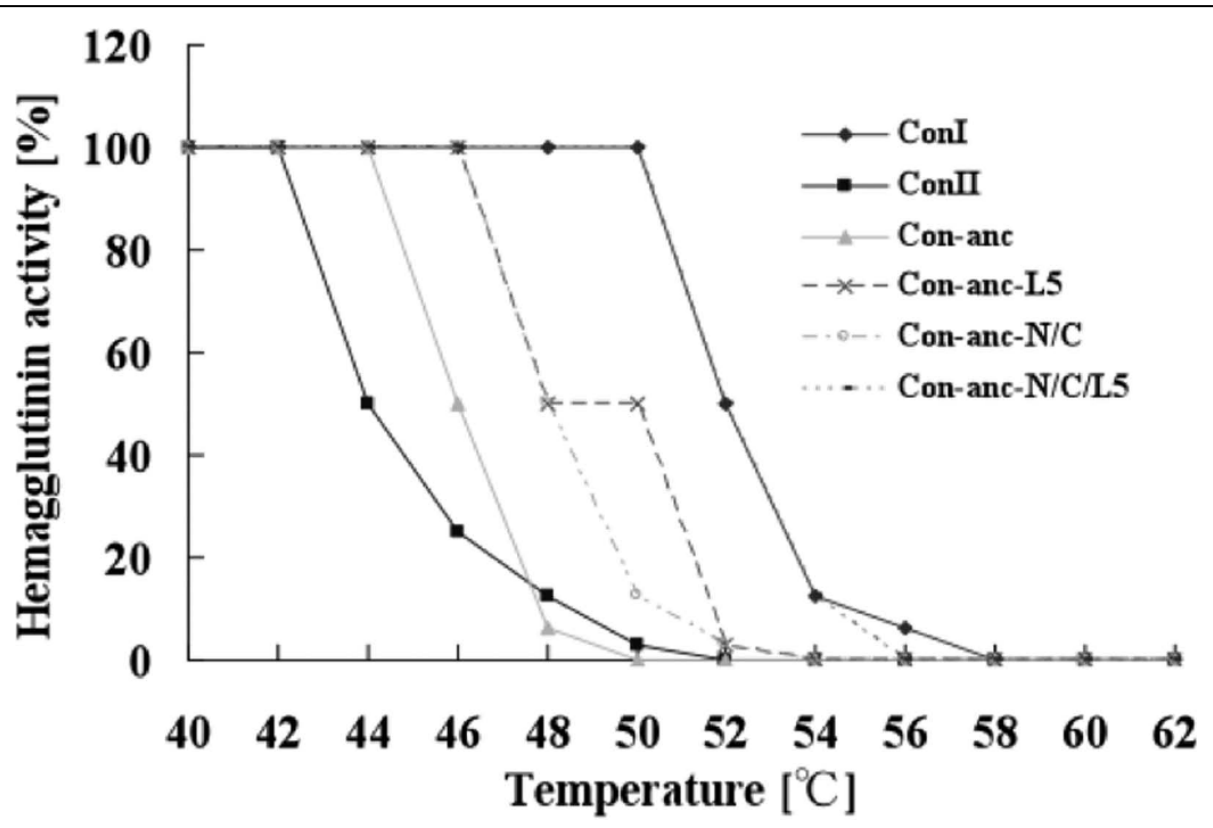

Figure 3 Thermal stabilities of Conl, Conll, Con-anc, and Con-anc mutants. The residual hemagglutination activities were measured after incubation at various temperatures for $30 \mathrm{~min}$. 
Table 1 Comparison of the dissociation constants $\left(K_{\mathrm{d}}\right)$ of Conl, Conll, Con-anc, and Con-anc mutants.

\begin{tabular}{|c|c|c|c|c|c|c|c|c|c|c|c|c|c|c|c|c|c|c|}
\hline \multirow{2}{*}{$\begin{array}{l}\text { Sugar } \\
\#\end{array}$} & \multicolumn{3}{|c|}{ Conl } & \multicolumn{3}{|c|}{ Conll } & \multicolumn{3}{|c|}{ Con-anc } & \multicolumn{3}{|c|}{ Con-anc-N/C } & \multicolumn{3}{|c|}{ Con-anc-L5 } & \multicolumn{3}{|c|}{ Con-anc-N/C/L5 } \\
\hline & $\begin{array}{r}K_{\mathrm{d}} \\
(\mu \mathrm{M})\end{array}$ & $\begin{array}{r}\text { ratio to } \\
\text { Con- } \\
\text { anc. }\end{array}$ & $\begin{array}{r}\text { ratio } \\
\text { to } \\
\text { Conl }\end{array}$ & $\begin{array}{r}K_{\mathrm{d}} \\
(\mu \mathrm{M})\end{array}$ & $\begin{array}{r}\text { ratio to } \\
\text { Con- } \\
\text { anc. }\end{array}$ & $\begin{array}{r}\text { ratio } \\
\text { to } \\
\text { Conl }\end{array}$ & $\begin{array}{r}K_{d} \\
(\mu \mathrm{M})\end{array}$ & $\begin{array}{r}\text { ratio to } \\
\text { Con- } \\
\text { anc. }\end{array}$ & $\begin{array}{r}\text { ratio } \\
\text { to } \\
\text { Conl }\end{array}$ & $\begin{array}{r}K_{d} \\
(\mu \mathrm{M})\end{array}$ & $\begin{array}{r}\text { ratio } \\
\text { to } \\
\text { Con- } \\
\text { anc. }\end{array}$ & $\begin{array}{r}\text { ratio } \\
\text { to } \\
\text { Conl }\end{array}$ & $\begin{array}{r}K_{d} \\
(\mu \mathrm{M})\end{array}$ & $\begin{array}{r}\text { ratio } \\
\text { to } \\
\text { Con- } \\
\text { anc. }\end{array}$ & $\begin{array}{r}\text { ratio } \\
\text { to } \\
\text { Conl }\end{array}$ & $\begin{array}{r}K_{\mathrm{d}} \\
(\mu \mathrm{M})\end{array}$ & $\begin{array}{r}\text { ratio } \\
\text { to } \\
\text { Con- } \\
\text { anc. }\end{array}$ & $\begin{array}{r}\text { ratio } \\
\text { to } \\
\text { Conl }\end{array}$ \\
\hline 01 & 0.50 & 10 & 1 & 3.8 & 1.4 & 0.13 & 5.2 & 1 & 0.10 & 13 & 0.41 & 0.04 & 3.2 & 1.6 & 0.16 & 1.7 & 3.1 & 0.30 \\
\hline 02 & 0.36 & 7 & 1 & 2.3 & 1.0 & 0.15 & 2.4 & 1 & 0.15 & 7.1 & 0.34 & 0.05 & 2.0 & 1.2 & 0.18 & 1.2 & 1.9 & 0.29 \\
\hline 03 & 0.24 & 7 & 1 & 1.4 & 1.1 & 0.17 & 1.6 & 1 & 0.15 & 4.9 & 0.33 & 0.05 & 1.3 & 1.2 & 0.18 & 0.78 & 2.1 & 0.31 \\
\hline 04 & 0.36 & 7 & 1 & 2.3 & 1.1 & 0.16 & 2.5 & 1 & 0.15 & 7.6 & 0.33 & 0.05 & 1.9 & 1.3 & 0.19 & 1.3 & 2.0 & 0.29 \\
\hline 05 & 0.58 & 8 & 1 & 4.0 & 1.1 & 0.14 & 4.6 & 1 & 0.13 & 14 & 0.32 & 0.04 & 3.2 & 1.4 & 0.18 & 2.0 & 2.3 & 0.29 \\
\hline 06 & 0.51 & 8 & 1 & 3.4 & 1.2 & 0.15 & 4.0 & 1 & 0.13 & 12 & 0.35 & 0.04 & 2.6 & 1.6 & 0.20 & 1.8 & 2.2 & 0.28 \\
\hline 09 & 0.51 & 9 & 1 & 3.8 & 1.2 & 0.13 & 4.7 & 1 & 0.11 & 14 & 0.34 & 0.04 & 3.0 & 1.6 & 0.17 & 1.9 & 2.4 & 0.26 \\
\hline 10 & 0.42 & 6 & 1 & 2.5 & 1.1 & 0.17 & 2.7 & 1 & 0.16 & 8.0 & 0.33 & 0.05 & 2.0 & 1.3 & 0.20 & 1.3 & 2.0 & 0.31 \\
\hline 11 & 0.37 & 7 & 1 & 2.3 & 1.1 & 0.16 & 2.5 & 1 & 0.15 & 7.3 & 0.34 & 0.05 & 2.0 & 1.3 & 0.19 & 1.3 & 1.9 & 0.28 \\
\hline 21 & 1.2 & 10 & 1 & 9.6 & 1.3 & 0.13 & 13 & 1 & 0.10 & 33 & 0.39 & 0.04 & 6.7 & 1.9 & 0.18 & 4.4 & 2.9 & 0.28 \\
\hline 22 & 1.4 & 11 & 1 & 12 & 1.3 & 0.12 & 15 & 1 & 0.09 & 46 & 0.32 & 0.03 & 7.8 & 1.9 & 0.18 & 4.2 & 3.5 & 0.32 \\
\hline 23 & - & - & - & - & - & - & - & - & - & - & - & - & - & - & - & - & - & \\
\hline 41 & 0.96 & 8 & 1 & 9.4 & 0.8 & 0.10 & 7.7 & 1 & 0.12 & 23 & 0.34 & 0.04 & 3.5 & 2.2 & 0.28 & 2.2 & 3.5 & 0.43 \\
\hline 42 & 0.31 & 8 & 1 & 2.5 & 1.0 & 0.12 & 2.6 & 1 & 0.12 & 6.5 & 0.40 & 0.05 & 1.3 & 2.0 & 0.24 & 0.74 & 3.5 & 0.42 \\
\hline 43 & 0.35 & 6 & 1 & 2.5 & 0.8 & 0.14 & 2.0 & 1 & 0.18 & 5.5 & 0.36 & 0.06 & 1.4 & 1.4 & 0.26 & 0.83 & 2.4 & 0.42 \\
\hline 26 & 6.8 & 4 & 1 & 28 & 1.0 & 0.25 & 27 & 1 & 0.26 & 69 & 0.39 & 0.10 & 18 & 1.5 & 0.37 & 12 & 2.2 & 0.55 \\
\hline 27 & - & - & - & - & - & - & - & - & - & - & - & - & - & - & - & - & - & \\
\hline 28 & 2.8 & 17 & 1 & 26 & 1.8 & 0.11 & 46 & 1 & 0.06 & 112 & 0.41 & 0.02 & 20 & 2.2 & 0.13 & 11 & 4.2 & 0.25 \\
\hline 29 & - & - & - & 51 & 4.7 & - & 242 & 1 & - & 332 & 0.73 & - & 168 & 1.4 & - & 215 & 1.1 & \\
\hline 30 & - & - & - & 66 & 3.0 & - & 196 & 1 & - & 364 & 0.54 & - & 190 & 1.0 & - & 696 & 0.3 & \\
\hline 31 & - & - & - & - & - & - & - & - & - & - & - & - & - & - & - & - & - & \\
\hline 32 & 4.5 & 8 & 1 & 18 & 2.0 & 0.25 & 37 & 1 & 0.12 & 74 & 0.50 & 0.06 & 22 & 1.7 & 0.21 & 14 & 2.6 & 0.32 \\
\hline 33 & - & - & - & - & - & - & - & - & - & - & - & - & - & - & - & - & - & \\
\hline 34 & 6.4 & 8 & 1 & 25 & 1.9 & 0.26 & 49 & 1 & 0.13 & 104 & 0.47 & 0.06 & 27 & 1.8 & 0.24 & 17 & 2.8 & 0.37 \\
\hline 38 & - & - & - & - & - & - & - & - & - & - & - & - & - & - & - & - & - & \\
\hline 39 & 2.3 & 24 & 1 & 31 & 1.7 & 0.07 & 54 & 1 & 0.04 & 116 & 0.47 & 0.02 & 20 & 2.8 & 0.12 & 8.1 & 6.7 & 0.28 \\
\hline 40 & - & - & - & 75 & 0.8 & - & 63 & 1 & - & 178 & - & - & 136 & - & - & 94 & - & \\
\hline 44 & 4.4 & 13 & 1 & 24 & 2.3 & 0.18 & 55 & 1 & 0.08 & 126 & 0.44 & 0.04 & 3.9 & 14 & 1.14 & 1.7 & 32 & 2. \\
\hline 45 & 13 & 13 & 1 & 122 & 1.4 & 0.11 & 171 & 1 & 0.08 & 550 & 0.31 & 0.02 & 24 & 7.3 & 0.55 & 12 & 15 & 1. \\
\hline 46 & 9.4 & 5 & 1 & 37 & 1.2 & 0.26 & 44 & 1 & 0.21 & 183 & 0.24 & 0.05 & 4.5 & 9.8 & 2.10 & 2.1 & 21 & 4.5 \\
\hline 47 & 3.8 & 9 & 1 & 43 & 0.8 & 0.09 & 34 & 1 & 0.11 & 115 & 0.30 & 0.03 & 12 & 2.7 & 0.31 & 5.6 & 6.1 & 0.69 \\
\hline 48 & 17 & 3 & 1 & 42 & 1.3 & 0.40 & 56 & 1 & 0.30 & 166 & 0.34 & 0.10 & 5.6 & 9.9 & 2.99 & 2.5 & 22 & 6 \\
\hline 49 & 10 & 6 & 1 & 44 & 1.4 & 0.23 & 62 & 1 & 0.16 & 158 & 0.39 & 0.06 & 37 & 1.7 & 0.27 & 19 & 3.3 & 0.53 \\
\hline 50 & - & - & - & - & - & - & - & - & - & - & - & - & - & - & - & - & - & \\
\hline
\end{tabular}

Sugar Con-anc-N/C/L5/L6 Con-anc-N/C/L5/L6/

\begin{tabular}{lllllll}
$\#$ & & & \multicolumn{4}{c}{ L3 } \\
\cline { 2 - 7 } & $\begin{array}{l}K_{\mathrm{d}} \\
(\mu \mathrm{M})\end{array}$ & $\begin{array}{l}\text { ratio to } \\
\text { Con- } \\
\text { anc. }\end{array}$ & $\begin{array}{l}\text { ratio } \\
\text { to } \\
\text { Conl }\end{array}$ & $\begin{array}{l}K_{\mathrm{d}} \\
(\mu \mathrm{M})\end{array}$ & $\begin{array}{l}\text { ratio to } \\
\text { Con- } \\
\text { anc. }\end{array}$ & $\begin{array}{l}\text { ratio } \\
\text { to } \\
\text { Conl }\end{array}$ \\
\hline 01 & 1.0 & 5.0 & 0.47 & 0.70 & 7.4 & 0.71 \\
02 & 0.77 & 3.1 & 0.46 & 0.49 & 4.9 & 0.73 \\
03 & 0.55 & 2.9 & 0.44 & 0.39 & 4.1 & 0.62 \\
04 & 0.75 & 3.3 & 0.48 & 0.49 & 5.1 & 0.74 \\
05 & 1.2 & 3.9 & 0.50 & 0.80 & 5.7 & 0.73 \\
06 & 1.1 & 3.6 & 0.46 & 0.73 & 5.5 & 0.70 \\
09 & 1.2 & 3.9 & 0.43 & 0.74 & 6.4 & 0.69 \\
10 & 0.86 & 3.1 & 0.48 & 0.61 & 4.4 & 0.68 \\
11 & 0.85 & 2.9 & 0.44 & 0.51 & 4.8 & 0.72
\end{tabular}




\begin{tabular}{|c|c|c|c|c|c|c|}
\hline 21 & 2.5 & 5.0 & 0.49 & 1.7 & 7.5 & 0.73 \\
\hline 22 & 2.7 & 5.4 & 0.51 & 1.9 & 7.6 & 0.71 \\
\hline 23 & - & - & - & - & - & - \\
\hline 41 & 1.3 & 5.9 & 0.73 & 1.0 & 7.7 & 0.96 \\
\hline 42 & 0.52 & 4.9 & 0.59 & 0.40 & 6.4 & 0.76 \\
\hline 43 & 0.53 & 3.7 & 0.66 & 0.35 & 5.5 & 0.99 \\
\hline 26 & 6.2 & 4.3 & 1.1 & 4.8 & 5.5 & 1.42 \\
\hline 27 & - & - & - & - & - & - \\
\hline 28 & 6.1 & 7.6 & 0.46 & 5.2 & 8.8 & 0.53 \\
\hline 29 & - & - & - & - & - & - \\
\hline 30 & - & - & - & - & - & - \\
\hline 31 & - & - & - & - & - & - \\
\hline 32 & 12 & 3.1 & 0.38 & 7 & 5.6 & 0.68 \\
\hline 33 & - & - & - & - & - & - \\
\hline 34 & 13 & 3.7 & 0.48 & 9 & 5.7 & 0.75 \\
\hline 38 & - & - & - & - & - & - \\
\hline 39 & 3.9 & 14 & 0.58 & 4 & 15 & 0.64 \\
\hline 40 & 28 & - & - & 238 & 0.27 & - \\
\hline 44 & 1.4 & 39 & 3.1 & 3.0 & 19 & 1.49 \\
\hline 45 & 7.1 & 24 & 1.8 & 15 & 11 & 0.87 \\
\hline 46 & 1.8 & 24 & 5.1 & 6.0 & 7.3 & 1.57 \\
\hline 47 & 4.1 & 8.3 & 0.94 & 3.0 & 11 & 1.30 \\
\hline 48 & 2.5 & 22 & 6.7 & 8.1 & 6.9 & 2.08 \\
\hline 49 & 11 & 5.9 & 0.95 & 8.7 & 7.2 & 1.16 \\
\hline 50 & - & - & - & - & & \\
\hline
\end{tabular}

Ratios of $K_{\mathrm{a}}\left(1 / K_{\mathrm{d}}\right)$ values of congerins and their mutants to those of Con-anc and Conl were calculated. PA sugar numbers are provided in Additional File 3: Supplemental Figure S1.

Con-anc-N/C/L5 with respect to almost all sugars, when compared with those of Con-anc. Although the binding affinity of Con-anc-N/C to sugars decreased, the $\mathrm{N}$ - and $\mathrm{C}$-terminal regions of ConI was found to increase the binding activity together with the introduction of the L5 sequence of ConI. Therefore, in terms of carbohydrate-binding activity, L5 should be the predominant structural element for high binding activity, and the Nand C-terminal regions may play an auxiliary role in carbohydrate binding by increasing the structural stability or slightly altering the structure. Con-anc-N/C/L5/L6 showed higher affinity toward almost all sugars than Con-anc-N/ C/L5 (Table 1). Interestingly, the specific binding activity of Con-anc mutants, namely, Con-anc-L5, Con-ancN/C/ L5, and Con-anc-N/C/L5/L6, were greatly increased against LNFP-II (\#44), LNFP-III (\#45), LNDFH (\#46), and A-heptasaccharide (\#48), all of which contained fucosylGlcNAc, by 20- to 30-fold when compared with the affinity of Con-anc, and by 3- to 7-fold when compared with that of ConI (Figure 4). These results suggest that the L5 and $\mathrm{L} 6$ regions of ConI may be involved in the high binding affinity to fucosyl-GlcNAc-containing sugars such as LNFP-II (\#44), LNFP-III (\#45), LNDFH (\#46), and A-heptasaccharide (\#48). On the other hand, the activity of Con-anc-N/C/L5/L6/L3 was reduced by approximately $30-50 \%$ of that of Con-anc-N/C/L5/L6 against these carbohydrates (Figure 4), although Con-anc-N/C/L5/L3 showed almost the same binding activity as Con-anc-N/C/ L5 (data not shown). These results suggest that Thr38/ Met38 residues in L3 cooperate with L6 to modulate the carbohydrate binding specificity.

Furthermore, the structural comparison of sugars, for which each mutant was either recognized specifically or not, showed that Con-anc-N/C/L5 and Con-anc-N/C/ L5/L6 increased the recognizing specificity to an $\alpha 1,4$ fucosylated $N$-acetyl glucosamine (Lewis $\mathrm{A}, \mathrm{Le}^{\mathrm{a}}$ ) but not $\alpha 1,3$-fucosylated $N$-acetyl glucosamine (Lewis $\mathrm{X}, \mathrm{Le}^{\mathrm{x}}$ ) (Table 2). This indicates that ConI has evolved via accelerated evolution under significant selection pressure to acquire the binding activity to specific carbohydrates including $\alpha 1,4$-fucosylated $N$-acetyl glucosamine. It is known that the fucosylation occurs throughout nature and is concerned with the cell-cell interaction and cell migration in the physiological and pathological processes ranging from fertilisation and development through to pathological events and cell death [28,29]. In pathogenic bacterium, the fucosylated oligosaccharides have been found in Helicobacter pylori, which is a 


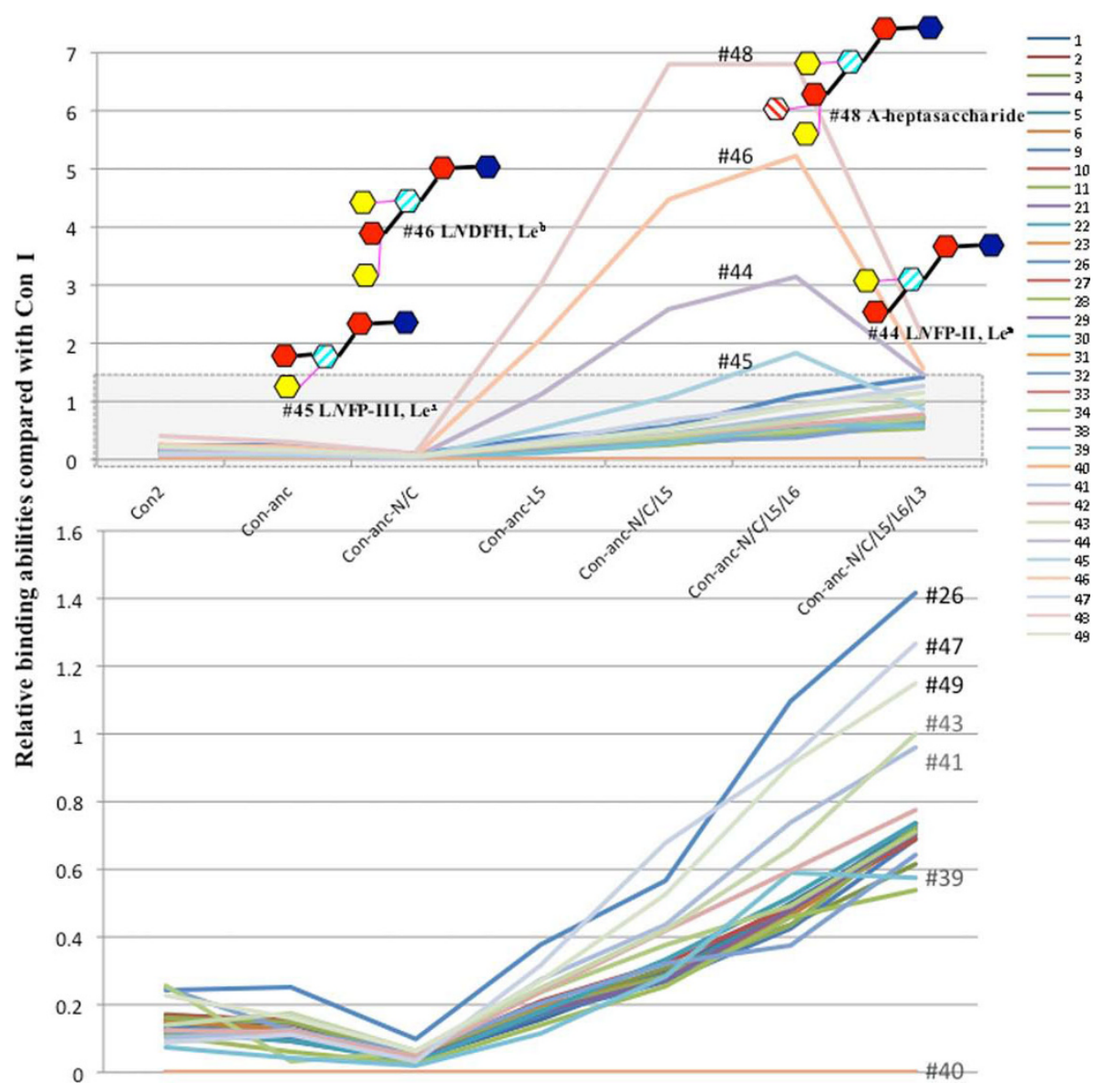

Figure 4 The relative sugar-binding activities of Con II and Con-anc mutants when compared with that of Con I. Scale for the PA sugars, except for LNFP-II, LNFP-III, LNDFH, and A-heptasaccharide (\#44, \#45, \#46, and \#48, respectively), was expanded. The PA sugar numbers are provided in Additional File 3: Supplemental Figure S1.

Table 2 Comparison of the relative sugar binding activities of Con-anc mutants, Con-anc-N/C/L5, Con-anc-N/C/L5/L6, and Con-anc-N/C/L5/L6/L3.

\begin{tabular}{|c|c|c|c|c|}
\hline \multirow[t]{2}{*}{ Compared sugars } & \multicolumn{3}{|c|}{ Ratio of relative binding activities } & \multirow[t]{2}{*}{ Different structure(s) between two compared sugars } \\
\hline & Con-anc N/C/L5 & Con-anc N/C/L5/L6 & Con-anc N/C/L5/L6/L3 & \\
\hline$\# 45 / \# 41$ & 2.48 & 2.48 & 0.9 & $\alpha 1,3-$ fucosyl(GlcNAc) \\
\hline \#43/\#42 & 1.01 & 1.11 & 1.29 & $\alpha 1,2-$ fucosyl(Gal) \\
\hline \#44/\#42 & $\underline{6.18}$ & $\underline{5.27}$ & 1.89 & $\alpha 1,4$-fucosyl(GlcNAc) \\
\hline \#46/\#42 & 10.7 & 8.76 & 2.02 & $\alpha 1,2-$ fucosyl(Gal)/ $\alpha 1,4-$ fucosyl(GlcNAc) \\
\hline \#47/\#42 & $\overline{1.62}$ & 1.55 & 1.63 & $\alpha 1,2-$ fucosyl(Gal)/ 1 1,3-GalNAc(Gal) \\
\hline \#48/\#42 & 16.2 & 11.4 & 2.71 & $\alpha 1,4$-fucosyl(GlcNAc)/ 1 1,2-fucosyl(Gal)/ $1,3-G a \mid N A c(G a l)$ \\
\hline \#46/\#43 & 10.6 & $\underline{7.91}$ & 1.57 & $\alpha 1,4$-fucosyl(GlcNAc) \\
\hline$\# 46 / \# 44$ & 1.73 & 1.66 & 1.07 & $\alpha 1,2-$ fucosyl(Gal) \\
\hline$\# 47 / \# 43$ & 1.61 & 1.4 & 1.27 & $\alpha 1,2-$ fucosyl(Gal) \\
\hline \#48/\#43 & 16.1 & $\underline{10.3}$ & 2.1 & $\alpha 1,4$-fucosyl(GlcNAc)/ $\alpha 1,3-$ GalNAc(Gal) \\
\hline \#48/\#46 & 1.52 & 1.3 & 1.34 & $\alpha 1,3-$ GalNAc(Gal) \\
\hline \#48/\#47 & 10 & 7.34 & 1.66 & $\alpha$ 1,4-fucosyl(GlcNAc) \\
\hline
\end{tabular}

PA-sugar numbers are provided in Additional File 3: Supplemental Figure S1. 
human pathogenic Gram-negative bacterium causing gastritis and gastric adenocarcinoma. Fucosylated antigens, $\mathrm{Le}^{\mathrm{x}}$ and $\mathrm{Le}^{\mathrm{y}}$, expressed on lipopolysaccharide of the microorganism play an important role in the infection, mimic host cell surface glycoconjugates and induce autoantibodies. Recently, fucose-specific lectins, F-type lectins, have been isolated from the serum from several fishes such as Anguilla japonica [30], Anguilla anguilla [31], Morone saxatilis [32], Sparus aurata [33], and Dicentrarchus labrax [34]. They have been proposed to play a role as molecular recognition factors in innate immunity. In the case for conger eel, F-type lectins have not yet been identified although C-type lectin and galectins have been isolated from serum and skin mucus $[35,13,14]$. These observations permit us to speculate that ConI may function as a surrogate of F-type lectin besides the function as galectin in conger eel.

On the other hand, ConII showed a binding affinity to a2,3-sialyl galactose-containing sugars such as GM3 [NeuAc] ( $N$-acetylneuraminic acid), GM3 [NeuGc] ( $\mathrm{N}$-glycolylneuraminic acid), and GD1a as described in a previous report [23], and ConI simply could not bind to GM3 and GD1a. Although Con-anc mutants, namely, Con-anc-N/C, Con-anc-L5, and Con-anc-N/C/L5, also showed binding affinities to $\alpha 2,3$-sialyl galactose-containing sugars-GM3 (NeuAc) (\#29), GM3 (NeuGc) (\#30), and GD1a (\#33)-with very low interactions when compared with ConII, Con-anc-N/C/L5/L6 and Conanc-N/C/L5/L6/L3 lost their binding activities against GM3 (NeuAc) (\#29), GM3 (NeuGc) (\#30), and GD1a (\#33), indicating that the L5 and L6 structures of ConII contribute to the recognition of $\alpha 2,3$-sialyl galactose
(Figure 5). The SPR analysis of Con-anc mutants using the GM3-immobilized sensor chip confirmed their binding affinity to $\alpha 2,3$-sialyl galactose-containing sugars (Table 3). Con-anc-N/C and Con-anc showed similar GM3-binding activity $\left(K_{\mathrm{d}}=4.9 \times 10^{-5}\right.$ and $6.8 \times 10^{-5} \mathrm{M}$, respectively). On the other hand, Con-anc-L5 showed decreased affinity to GM3 $\left(K_{\mathrm{d}}=2.6 \times 10^{-4} \mathrm{M}\right)$, and Con-anc-N/C/L5 showed negligible affinity to GM3 $\left(K_{\mathrm{d}}=1.0 \times 10^{-2} \mathrm{M}\right)$. These observations indicate that the L5 and L6 regions of ConI are responsible for the strong binding affinities to $\alpha 1,4$-fucosylated $N$-acetyl glucosamine in exchange for the binding affinities to $\alpha 2,3$-sialyl galactose.

\section{Molecular dynamics (MD) simulation}

L3 and L6 regions do not directly interact with the bound sugar in the crystal structure of ConI, although the mutants of these loops demonstrated significant alterations in the sugar-binding activity. To investigate the roles of these loops in sugar recognition, a 4-ns MD simulation of the dimeric ConI-lactose complex was performed. Cooperative behaviors within and between the loops and sugar-binding residues were evaluated as the correlation coefficients of the hydrogen bond formation rates during the simulation. As a result, high correlations within and between L3 and L5 were detected (Figure 6). Furthermore, the hydrogen bonds between L3 and L5 revealed a correlation with the bonds connecting Arg28 and Arg47 to lactose. On the other hand, L6 cooperated with L4 through the inter-loop connections mediated by L2, because L2-L6 and L2-L4 hydrogen bonds were highly correlated (Figure 6). This cooperation of loops,

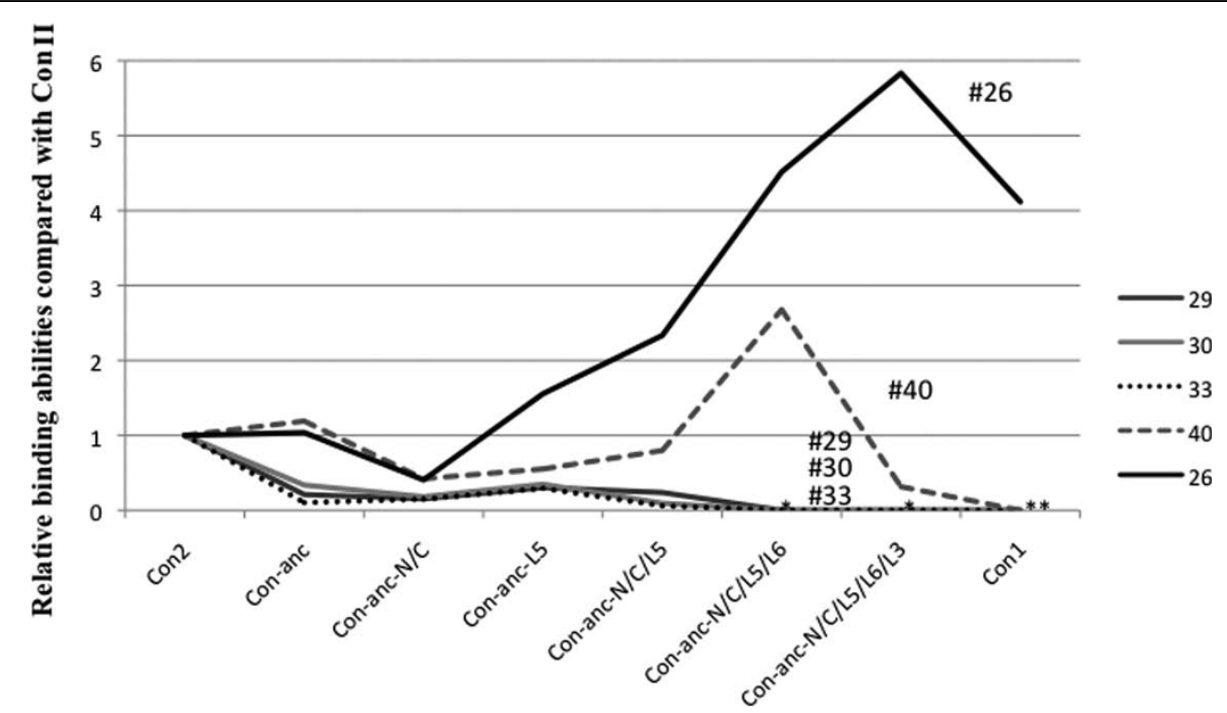

Figure 5 The relative sugar-binding activities of Con I and Con-anc mutants when compared with that of Con II. Asterisk $\left(^{*}\right)$ indicates no binding activities against sugars \#29, \#30, and \#33, and asterisks (**) indicate no activities against \#40 in addition to \#29, \#30, and \#33. The PA sugar numbers are provided in Additional File 3: Supplemental Figure S1. 
Table 3 Comparison of the dissociation constants $\left(K_{\mathrm{d}}\right)$ of Con-anc, Con-anc-N/C, Con-anc-L5, and Con-anc-N/C/L5 to the immobilized GM3.

\begin{tabular}{ll}
\hline & $\boldsymbol{K}_{\mathbf{d}}(\mathbf{M})$ \\
\hline Con-anc & $6.8 \times 10^{-5}$ \\
Con-anc-N/C & $4.9 \times 10^{-5}$ \\
Con-anc-L5 & $2.6 \times 10^{-4}$ \\
Con-anc-N/C/L5 & $1.0 \times 10^{-2}$ \\
\hline
\end{tabular}

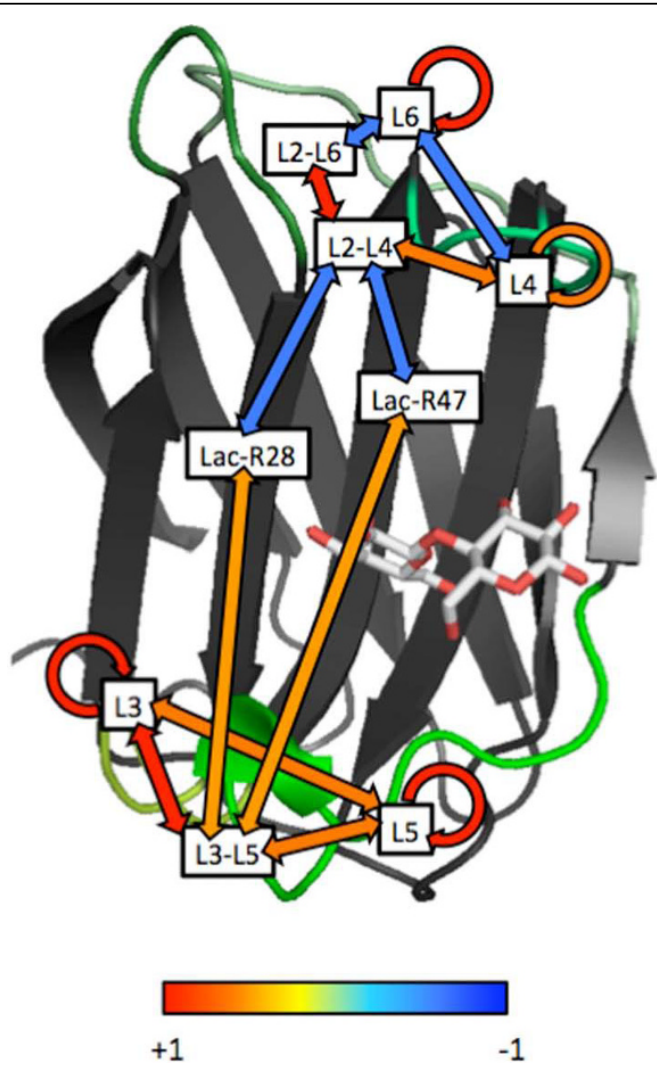

Figure 6 Correlation of inter- and intra-loop hydrogen bond formation during MD simulation. Correlation coefficients of hydrogen bond formation rates are shown on the structure of Conl. $L 3, L 4, L 5$, and $L 6$ represent the intra-loop bonds. $L 2-L 4, L 2-L 6$, and L3-L5 indicate the inter-loop bonds. Lac-R28 and Lac-R47 are the bonds between the residues and lactose. The colors of the arrows connecting the labels indicate the degree of correlation from positive (red) to negative (blue), as shown in the color bar.

L6-L2-L4, showed a negative correlation with the lactosebinding hydrogen bonds, Lac-R28 and Lac-R47. These observations implied that the L6-L2-L4 and L3-L5 networks of the loops might have an antagonistic effect on sugar binding. As L4 and L5 were directly involved in sugar binding, these results suggested that the structural compatibility between loops L3-L5 and L6-L2-L4 might affect the sugar-binding activity, as observed in the Conanc mutants.

\section{Apoptotic activities of Con-anc mutants}

Figure 7 showed the dose-dependent cytotoxic effects of ConI, ConII, and Con-anc and its mutants on apoptotic activities for Jurkat cells. ConI showed a stronger apoptosis-inducing activity than ConII, similar to their carbohydrate-binding activities as described in the previous study, we found that ConI and ConII could strongly induce apoptosis in the human T-cell lines and Jurkat cells, and that their apoptotic activities are induced via lectin-carbohydrate interactions [36]. In the present study, the cytotoxic activities of Con-anc mutants were assayed using the Jurkat cells to evaluate the correlations between the apoptotic activities and carbohydrate-binding specificities of Con-anc and its mutants, in addition to the present-day congerins, ConI and ConII. The apoptotic activities of Con-anc and its mutants were positively correlated with their agglutinating activities, suggesting that Con-anc-N/C/L5/L6 and Con-anc-N/C/L5/L6/L3, whose carbohydrate-binding activities were almost the same $(50-100 \%)$ as that of ConI, could produce apoptosis-inducing activities comparable with those of ConI. On the other hand, Conanc, which had similar sugar-binding activity as that of ConII, showed a lower apoptosis-inducing activity than ConII (Figure 7).

Numerous galectins have been indicated as the functional molecules that control the fate of a cell $[5,7,8,37,38]$. In particular, there are many reports indicating galectins as apoptosis-inducing factors, e.g., galectin-1 [37], galectin-2 [39], galectin-3 (exogenous) [40], galectin-8 [41,42], and galectin-9 [43]. It is known that galectin-1-induced apoptosis requires its binding to the glycoproteins, including CD7, CD43, and CD45, on the surface of the T-cells [44-46]. These glycoproteins have some $O$-linked and/or $N$-linked glycans, and are modified by some glycosyltransferases via alteration of their susceptibility to galectin-1-induced apoptosis [47,48]. In addition, congerins also bind to CD7, CD43, and CD45. Neuraminidase-treated Jurkat cells were 3- and 5-fold more susceptible to ConI and ConII, respectively, than the non-treated Jurkat cells (unpublished data), indicating that the carbohydrate structure on the T-cell surface is important for the induction of apoptosis by congerins.

\section{Evolutionary process of congerins from ancestral gene}

At the gene duplication event, the ancestral congerin Con-anc showed comparable thermostability and similar carbohydrate-binding specificities, with those of ConII, except for $\alpha 2,3$-sialyl galactose-containing sugars such as GM3 and GD1a. Thus, the gene encoding ConII has evolved in an accelerated manner from the ancestral gene to acquire the ability specific to pathogenic marine bacteria via the recognition of $\alpha 2,3$-sialyl galactose $[20,23]$. On the other hand, ConI has evolved from the 


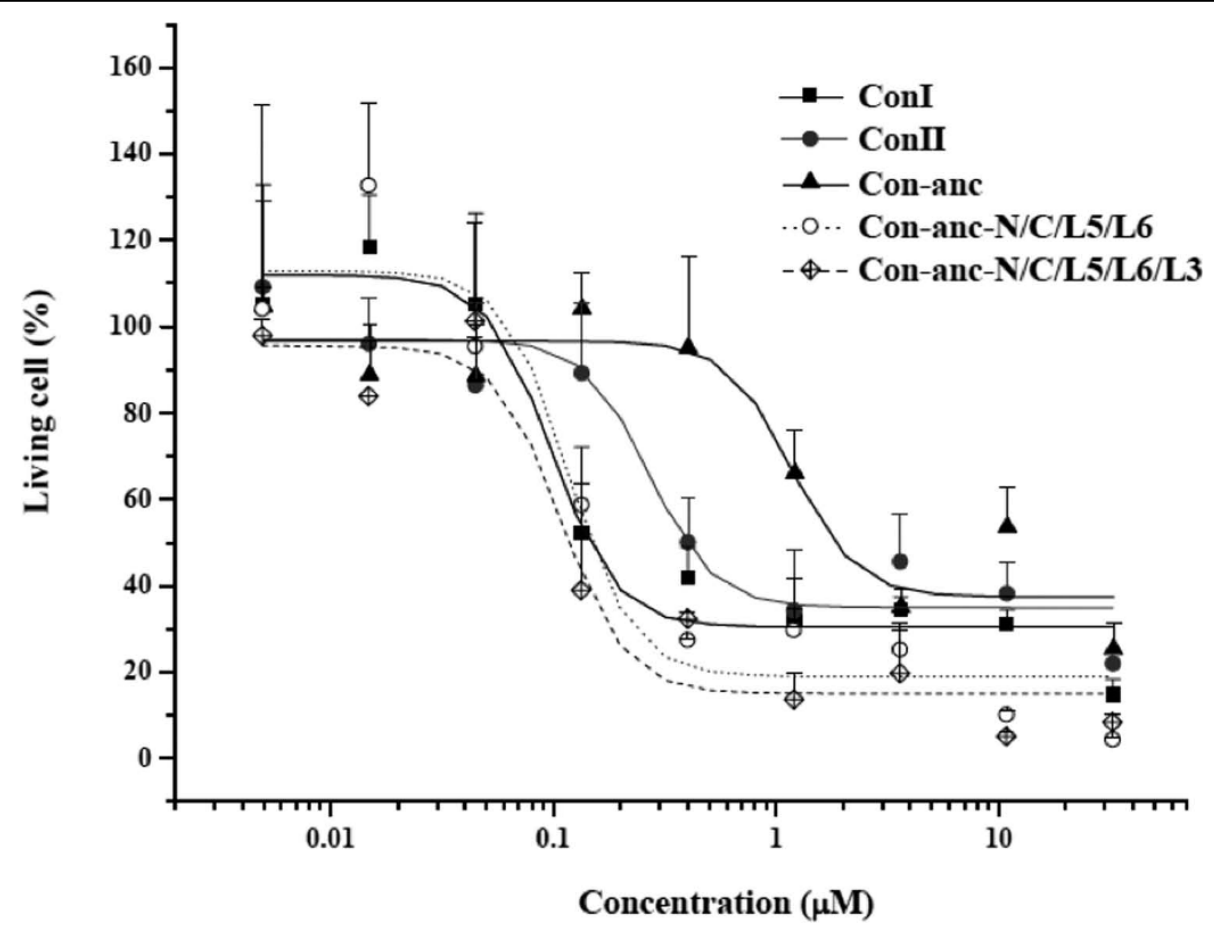

Figure 7 Cytotoxic effects of Conl, Conll, and Con-anc mutants on Jurkat cells. Solid square and continuous line represent Conl; solid circle and continuous line represent Conll; solid triangle and continuous line indicate Con-anc; hollow circle and dotted line indicate Con-anc-N/C/L5/ L6; and hollow diamond and broken line represent Con-anc-N/C/L5/L6-T38 M. The calculated ED 50 values (50\% effective dose) were as follows: Conl, 0.098; Conll, 0.27; Con-anc, 1.2; Con-anc-N/C/L5/L6, 0.12; and Con-anc-N/C/L5/L6/L3, 0.11.

ancestral congerin Con-anc to increase the binding activity against various sugars by modifying the $\mathrm{N}$ - and $\mathrm{C}$-termini and L5, L6, and L3 regions. Particularly, modifying the L5 and L6 regions of Con-anc to ConI showed strong binding specificities against $\alpha 1,4$-fucosylated $N$-acetyl glucosamine. These findings emphasize that the carbohydrate-binding ability and the specificities of galectins can be controlled by modifying the loop structures.

In general, the rational designing of protein is a conventional and useful method to study the structurefunction relationship of the protein with the partial molecular evolutionary information such as sequence alignments. However, it is difficult to predict and determine the effects of various mutations if several amino acids synergistically act as structural factors and exert multiple effects. In the present study, tracing analysis of molecular evolution of galectins by using ancestral gene and its mutated forms has enabled the more direct investigation of the structure-function relationship of proteins. In fact, we have elucidated the correlations between the molecular evolution (or amino acid substitutions) and functional diversification of ConI (Figure 8), which have revealed the detailed structural elements responsible for ligand specificity to LNFP-II, LNFP-III, LNDFH, and A-heptasaccharide (\#44, \#45, \#46, and \#48), respectively.

\section{Conclusions}

The tracing analysis of molecular evolution, a protein engineering approach employing the reconstruction of probable ancestral forms based on phylogenetic trees and their mutants, is a powerful approach that not only reveals the molecular evolution process and determinants of selection pressures, but also helps to study the structure-function relationships of proteins.

\section{Methods}

\section{Design and preparation of chimera mutants of Con-anc} and Conl

The Con-anc mutants described in this study are summarized in Figure 1 and Additional File 1: Supplemental Table S1. These mutants were constructed by inverted polymerase chain reaction (PCR) amplification with some modifications [49], using PrimeSTAR HS DNA polymerase (TaKaRa Bio Inc., Japan) containing 2 ng of template DNA, $200 \mu \mathrm{M}$ of each dNTP, and $0.3 \mu \mathrm{M}$ of each primer. The pTV-Con-anc [23] and mutated pTVCon-anc plasmids were used as templates, and oligonucleotide primers containing unique restriction enzyme and mutation sites were used for PCR (Additional File 2: Table S2). The reaction mixtures were cycled 30 times, with each cycle running at $98^{\circ} \mathrm{C}$ for $10 \mathrm{~s}, 55^{\circ} \mathrm{C}$ for $15 \mathrm{~s}$, and $72^{\circ} \mathrm{C}$ for $3 \mathrm{~min} 30 \mathrm{~s}$. The mutagenized 


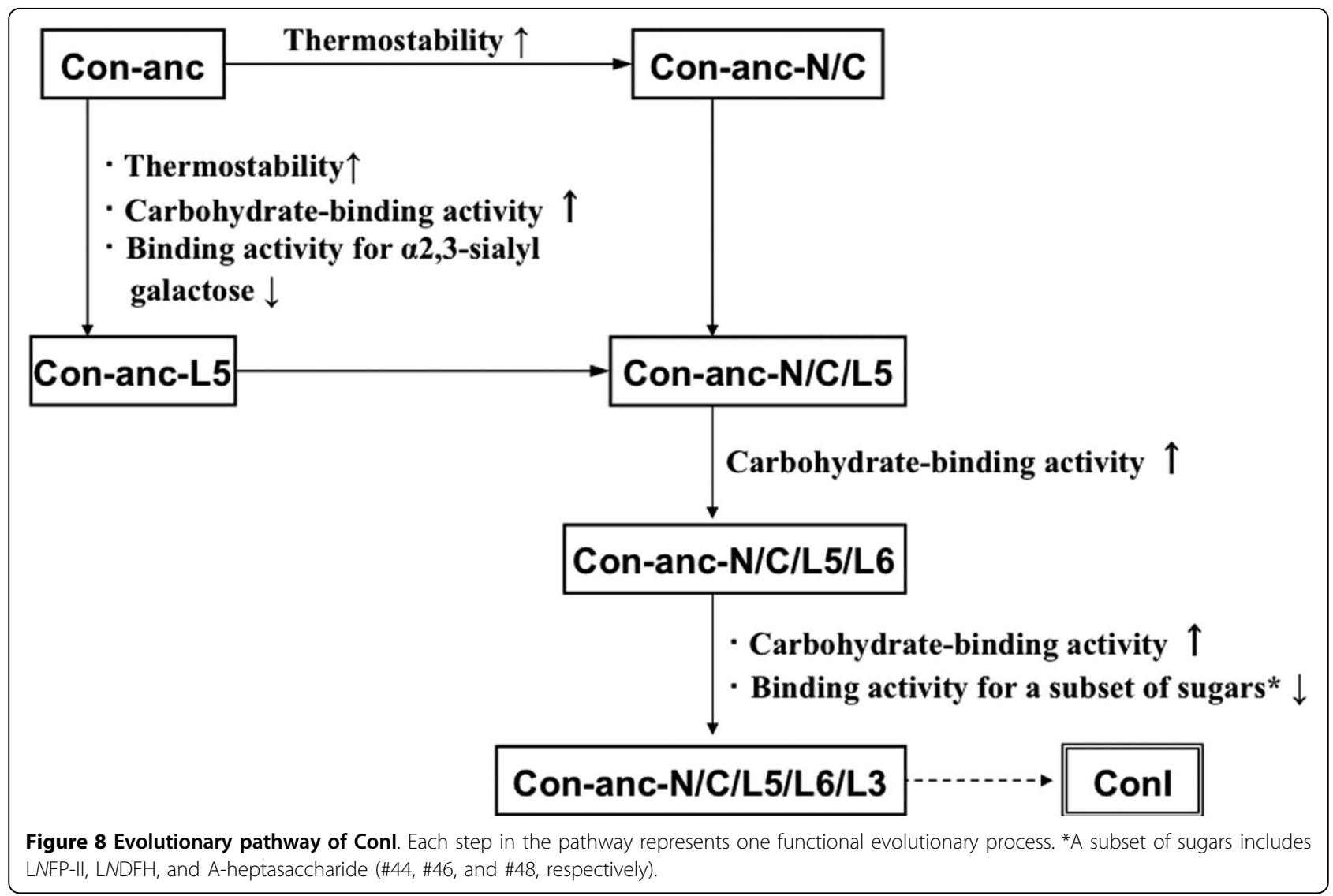

PCR products were purified by agarose gel electrophoresis, using Wizard ${ }^{\circledR}$ SV Gel and PCR Clean-Up System (Promega, USA), and subsequently digested with a unique restriction enzyme. The DNA fragment was selfligated and then transformed into competent Escherichia coli JM109. The nucleotide sequences of the mutant plasmids were confirmed by DNA sequencing. Recombinant Con-anc mutants were prepared by a method previously reported for Con-anc [23]. In brief, each mutant was purified by affinity chromatography on an $\mathrm{HCl}$-treated Sepharose 4B column (GE Healthcare, UK), followed by anion-exchange chromatography on a 5-ml HiTrap $\mathrm{Q}$ column (GE Healthcare). The purity of each mutant was confirmed by sodium dodecyl sulfate-polyacrylamide gel electrophoresis (SDS-PAGE). The phylogenetic tree of galectins including the chimera mutants between Con-anc and ConI was constructed by the maximum likelihood (ML) method in the PAML software package [50] using their amino acid sequences. Sequences data of galectins were retrieved from SwissProt databases. The entry codes for amino acid sequences are, respectively: ConI, leg1_conmy (p26788); ConII, leg2_conmy (q9yic2); BTG1 bovine galectin-1, leg1_bovin (p11116); HSG1 human galectin-1, leg1_human (p09382);
HSG2 human galectin-2, leg2_humen (p05162); XLG1 Xenopus galectin-1, q98ud4.

\section{Thermostability measurements}

Thermostabilities of Con-anc mutants were assessed by their residual hemagglutination activities using $2 \%$ rabbit erythrocytes plated on 96-well microtiter plates after incubation for $30 \mathrm{~min}$ at various temperatures ranging from 38 to $62^{\circ} \mathrm{C}$ in $50-\mathrm{mM}$ Tris- $\mathrm{HCl}$ buffer ( $\mathrm{pH} 7.5$ ), followed by cooling on ice. The experiment was performed in duplicate, and separately repeated three times.

\section{Carbohydrate-binding properties}

The carbohydrate-binding specificities and activities of Con-anc mutants were determined by frontal affinity chromatography (FAC) [51-53] in the same manner as that adopted for Con-anc [23]. The structures of the 34 kinds of pyridylaminated (PA) oligosaccharides used in FAC analysis are shown in Additional File 3: Supplemental Figure S1. In the SPR analysis, lyso-GM3 (Takara Bio Inc.) was immobilized on the sensor chip CM5 (GE Healthcare) via amino group, using carbodiimide chemistry, according to the manufacturer's manual. 


\section{Molecular dynamics simulation}

The coordinates of the ConI-lactose complex were retrieved from the Protein Data Bank (PDB code 1c1l), and the dimer structure was constructed on the basis of the biological unit matrix. Molecular dynamics (MD) simulation was performed for $4 \mathrm{~ns}$ using the SANDER module of AMBER 9 program suite. The AMBER03 force field [54] and GLYCAM 04 parameter set were used for the protein molecules and lactose, respectively. The system was solvated with TIP3P water molecules. To maintain the overall electrostatic neutrality conditions, $\mathrm{Na}^{+}$ions were added to the simulated systems. The initial unfavorable atomic contacts were removed by energy minimization with 1500 steps. The simulation was then started at $5 \mathrm{~K}$, with the initial velocities adopted from a Maxwellian distribution, followed by heating from 5 to $300 \mathrm{~K}$ over 50 ps. Subsequently, a 100-ps equilibration was performed at 300 $K$. Electrostatic interactions were calculated without distance cutoff by using the particle-mesh Ewald method [55]. The SHAKE algorithm was applied to constrain the bond lengths with hydrogen atoms [56]. The MD trajectories were analyzed using the PTRAJ module of AMBER. The correlation coefficients of cooperative hydrogen-bond formation were evaluated to detect the relationships between the loops (L2, L3, L4, L5, and L6) and sugar-binding sites (Arg28 and Arg47). The first 3-ns trajectory was divided into 200 -ps (20 steps) bins, and the formation rates within the time-bins were calculated for each hydrogen bond that showed a 10-90\% overall formation rate, excluding the transiently or permanently formed ones. The formation rate is the fraction of the snapshot structures that have the objective hydrogen bond in the total structures within the time-bin. The correlation coefficients for the pairs of hydrogen bonds were evaluated from the arrays of the formation rates. The correlation coefficient can be defined as

$$
r_{x y}=\Sigma\left(x_{i}-<x>_{i}\right)\left(y_{i}-<y>_{i}\right) /\left\{\Sigma\left(x_{i}-<x>_{i}\right)^{2} \Sigma\left(y_{i}-<y>_{i}\right)^{2}\right\}^{1 / 2},
$$

where, $x_{i}$ and $y_{i}$ are the formation rates of the hydrogen bonds $x$ and $y$ within the time bin $i$, respectively. The coefficients were averaged within and between the loops or sugar-binding residues.

\section{Cell culture and in vitro cell assays of Con-anc and its mutants}

The cytotoxic activities of Con-anc and its mutants were assessed by using Jurkat cells $[57,58]$ as the target cells. The Jurkat cells were maintained in a RPMI-1640 medium supplemented with $10 \%$ fetal bovine serum and $1 \%$ antibiotic-antimycotic solution at $37^{\circ} \mathrm{C}$ in $5 \%$ $\mathrm{CO}_{2}$ atmosphere. The Jurkat cells were grown in 96-well microtiter plates for the assay. Three-fold serial dilutions of Con-anc or its mutants were added to the confluent cells. After culturing for $24 \mathrm{~h}$ at $37^{\circ} \mathrm{C}$ in $5 \%$ $\mathrm{CO}_{2}$ atmosphere, the cell viability was evaluated using the cell proliferation reagent WST-1 (Dojindo, Japan), according to the manufacturer's instructions. Subsequently, the chromophores of WST-1 were measured by absorbance at $450 \mathrm{~nm}$. The assay was performed in triplicate, and confirmed separately three times to assess the reproducibility.

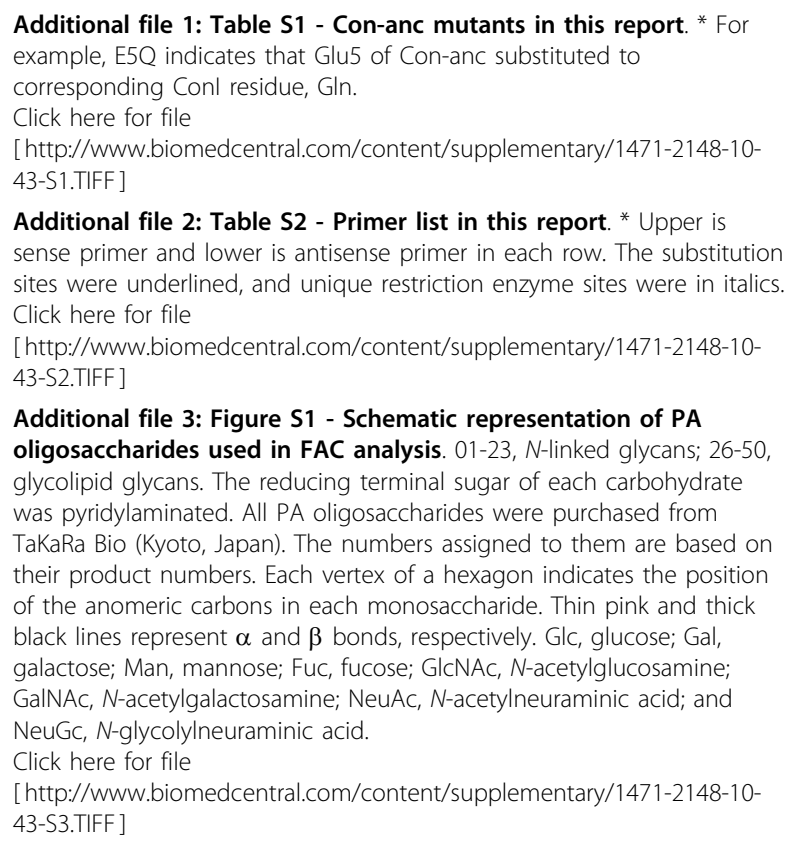

\section{Acknowledgements}

This work was supported by a Grant-in-Aid for Scientific Research (B) from the Ministry of Education, Science, Sports and Culture [14360045 to TO], and a research fellowship from the Japan Society for the Promotion of Science [06J05155 to AKo]

\section{Author details}

'Department of Biomolecular Science, Graduate School of Life Sciences, Tohoku University, Sendai 981-8555, Japan. ${ }^{2}$ Nagahama Institute of BioScience and Technology and Japan Science and Technology Agency, Biolnfomatic Research Division, Nagahama, Shiga 526-0829, Japan.

\section{Authors' contributions}

TO, AKo, TS and KM designed research. AKo, SY and TO performed molecular and biochemical experiments. TS and AKi performed molecular dynamics simulation and bioinformatics studies. TO, AKo and TS wrote the paper.

Received: 6 November 2009 Accepted: 14 February 2010

Published: 14 February 2010

\section{References}

1. Nei M: Molecular Evolutionary Genetics Columbia University Press, NY 1987.

2. Hartl DL, Clark AG: Principles of Population Genetics Sinauer Associates, Sunderland, MA, 31997.

3. Barondes SH, Castronovo V, Cooper DNW, Cummings RD, Drickamer K, Felzi T, Gitt MA, Hirabayashi J, Hughes C, Kasai K, Leffler H, Liu F-T, Lotan R, Mercurio AM, Monsigny M, Pillai S, Poirer F, Raz A, Rigby PWJ, Rini JM, 
Wang JL: Galectins: A family of animal $\beta$-galactoside-binding lectins. Cell 1994, 76:597-598.

4. Cooper DN, Barondes SH: God must love galectins; He made so many of them. Glycobiology 1999, 9:979-984.

5. Liu FT, Patterson RJ, Wang JL: Intracellular functions of galectins. Biochim Biophys Acta 2002, 1572:263-273.

6. Sato S: Galectins as molecules of danger signal, which could evoke an immune response to infection. Trends Glycosci Glycotechnol 2002, 14:285-301.

7. Elola MT, Wolfenstein-Todel C, Troncoso MF, Vasta GR, Rabinovich GA: Galectins: Matricellular glycan-binding proteins linking cell adhesion, migration, and survival. Cell Mol Life Sci 2007, 64:1679-1700.

8. Yang RY, Rabinovich GA, Liu FT: Galectins: Structure, function and therapeutic potential. Expert Rev Mol Med 2008, 10:e17.

9. Cooper DN: Galectinomics: Finding themes in complexity. Biochim Biophys Acta 2002, 1572:209-231.

10. Leffler H, Carlsson S, Hedlund M, Qian Y, Poirier F: Introduction to galectins. Glycoconj J 2004, 19:433-440.

11. Hirabayashi J, Kasai K: The family of metazoan metal-independent $\beta$-galactoside-binding lectins: Structure, function and molecular evolution. Glycobiology 1993, 3:297-304

12. Kamiya $\mathrm{H}$, Muramoto $\mathrm{K}$, Goto R: Purification and properties of agglutinins from conger eel, Conger myriaster (Brevoort), skin mucus. Dev Comp Immunol 1988, 12:309-318.

13. Muramoto K, Kamiya H: The amino-acid sequence of a lectin from conger eel, Conger myriaster, skin mucus. Biochim Biophys Acta 1992, 1116:129-136.

14. Muramoto K, Kagawa D, Sato T, Ogawa T, Nishida Y, Kamiya H: Functional and structural characterization of multiple galectins from the skin mucus of conger eel, Conger myriaster. Comp Biochem Physiol B 1999, 123:33-45.

15. Ogawa T, Ishii C, Kagawa D, Muramoto K, Kamiya H: Accelerated evolution in the protein-coding region of galectin CDNAs, congerin I and congerin II, from skin mucus of conger eel (Conger myriaster). Biosci Biotechnol Biochem 1999, 63:1203-1208.

16. Nakamura O, Saeki M, Kamiya H, Muramoto K, Watanabe T: Galectin containing cells in the skin and mucosal tissues in Japanese conger eel, Conger myriaster: An immunohistochemical study. Dev Comp Immunol 2001, 25:431-437.

17. Nakamura O, Matsuoka H, Ogawa T, Muramoto K, Kamiya H, Watanabe T: Opsonic effect of congerin, a mucosal galectin of the Japanese conger, Conger myriaster (Brevoort). Fish Shellfish Immunol 2006, 20:433-435.

18. Nakamura O, Inaga Y, Suzuki S, Tsutsui S, Muramoto K, Kamiya H, Watanabe T: Possible immune functions of congerin, a mucosal galectin, in the intestinal lumen of Japanese conger eel. Fish Shellfish Immunol 2007, 23:683-692.

19. Shirai T, Mitsuyama C, Niwa Y, Matsui Y, Hotta H, Yamane T, Kamiya H, Ishii C, Ogawa T, Muramoto K: High-resolution structure of the conger eel galectin, congerin I, in lactose-liganded and ligand-free forms: Emergence of a new structure class by accelerated evolution. Structure 1999, 7:1223-1233.

20. Shirai T, Matsui Y, Shionyu-Mitsuyama C, Yamane T, Kamiya H, Ishii C, Ogawa T, Muramoto K: Crystal structure of a conger eel galectin (Congerin II) at $1.45 \AA$ resolution: Implication for the accelerated evolution of a new ligand-binding site following gene duplication. $J \mathrm{Mol}$ Biol 2002, 321:879-889.

21. Ogawa T, Shirai T, Shionyu-Mitsuyama C, Yamane T, Kamiya H, Muramoto K: The speciation of conger eel galectins by rapid adaptive evolution. Glycoconj J 2004, 19:451-458.

22. Shirai T, Shionyu-Mitsuyama C, Ogawa T, Muramoto K: Structure based studies of the adaptive diversification process of congerins. Mol Diver 2006, 10:567-573.

23. Konno A, Ogawa T, Shirai T, Muramoto K: Reconstruction of a probable ancestral form of conger eel galectins revealed their rapid adaptive evolution process for specific carbohydrate recognition. Mol Biol Evol 2007, 24:2504-25142

24. Kyte J, Doolittle RF: A simple method for displaying the hydropathic character of a protein. J Mol Biol 1982, 157:105-132.

25. Wigley DB, Clarke AR, Dunn CR, Barstow D, Atkinson T, Chia W, Muirhead H, Holbrook J: The engineering of a more thermally stable lactate dehydrogenase by reduction of the area of a water-accessible hydrophobic surface. Biochim Biophys Acta 1987, 916:145-148.
26. Fersht $A$, Serrano L: Principles of protein stability derived from protein engineering experiments. Curr Opin Struct Biol 1993, 3:75-83.

27. Shionyu-Mitsuyama C, Ito Y, Konno A, Miwa Y, Ogawa T, Muramoto K, Shirai T: In vitro evolutionary thermostabilization of congerin II: A limited reproduction of natural protein evolution by artificial selection pressure. J Mol Biol 2005, 347:385-397.

28. Staudacher $\mathrm{E}$, Altmann $\mathrm{F}$, Wilson IBH, März L: Fucose in N -glycans: from plant to man. Biochim Biophys Acta 1999, 1473:216-236.

29. Becker DJ, Lowe JB: Fucose: biosynthesis and biological function in mammals. Glycobiology 2003, 13:41R-53R.

30. Honda S, Kashiwagi M, Miyamoto K, Takei Y, Hirose S: Multiplicity, structures, and endocrine and exocrine natures of eel fucose-binding lectins. J Biol Chem 2000, 275:33151-33157.

31. Bianchet MA, Odom EW, Vasta GR, Amzel LM: A novel fucose recognition fold involved in innate immunity. Nat Struct Biol 2002, 9:628-634

32. Odom E, Vasta GR: Characterization of a binary tandem domain F-type lectin from striped bass (Morone saxatilis). J Biol Chem 2006, 281:1698-1713.

33. Cammarata M, Benenati G, Odom EW, Salerno G, Vizzini A, Vasta GR, Parrinello N: Isolation and characterization of a fish F-type lectin from gilt head bream (Sparus aurata) serum. Biochim Biophys Acta 2007 1770:150-155.

34. Salerno G, Parisi MG, Parrinello D, Benenati G, Vizzini A, Vazzana M, Vasta GR, Cammarata M: F-type lectin from the sea bass (Dicentrarchus labrax): Purification, cDNA cloning, tissue expression and localization, and opsonic activity. Fish Shellfish Immunol 2009, 27:143-153.

35. Tsutsui S, Iwamoto K, Nakamura O, Watanabe T: Yeast-binding C-type lectin with opsonic activity from conger eel (Conger myriaster) skin mucus. Mol Immunol 2007, 44:691-702.

36. Ogawa T, Yonemaru S, Naganuma T, Hirabayashi J, Kasai K, Muramoto K: Strong Induction of Apoptosis of T Cell Lines by Conger Eel Galectins. Biomolecular Chemistry-A Bridge for the Future Tokyo, Maruzen Co. Ltd 2003, 134-137.

37. Perillo NL, Pace KE, Seilhamer JJ, Baum LG: Apoptosis of T cells mediated by galectin-1. Nature 1995, 378:736-739.

38. Pace KE, Lee C, Stewart PL, Baum LG: Restricted receptor segregation into membrane microdomains occurs on human $T$ cells during apoptosis induced by galectin-1. J Immunol 1999, 163:3801-3811.

39. Sturm A, Lensch M, André $\mathrm{S}$, Kaltner $\mathrm{H}$, Wiedenmann B, Rosewicz $\mathrm{S}$, Dignass UA, Gabius HJ: Human galectin-2: Novel inducer of T cell apoptosis with distinct profile of caspase activation. J Immunol 2004, 173:3825-3837.

40. Fukumori T, Takenaka Y, Yoshii T, Kim H-RC, Hogan V, Inohara H, Kagawa S, Raz A: CD29 and CD7 Mediate Galectin-3-Induced Type IIT-Cell Apoptosis. Cancer Res 2003, 63:8302-8311.

41. Hadari YR, Arbel-Goren R, Levy Y, Amsterdam A, Alon R, Zakut R, Zick Y: Galectin-8 binding to integrins inhibits cell adhesion and induces apoptosis. J Cell Sci 2000, 113:2385-2397.

42. Norambuena A, Metz C, Vicuna L, Silva A, Pardo E, Oyanadel C, Massardo L, Gonzalez A, Soza A: Galectin-8 Induces Apoptosis in Jurkat T Cells by Phosphatidic Acid-mediated ERK1/2 Activation Supported by Protein Kinase A Down-regulation. J Biol Chem 2009, 284:12670-12679.

43. Kashio Y, Nakamura K, Abedin MJ, Seki M, Nishi N, Yoshida N, Nakamura T, Hirashima M: Galectin-9 induces apoptosis through the calcium-calpaincaspase-1 pathway. J Immunol 2003, 170:3631-3636.

44. Pace KE, Hahn HP, Pang M, Nguyen JT, Baum LG: Cutting edge: CD7 delivers a pro-apoptotic signal during galectin-1-induced $T$ cell death. J Immunol 2000, 165:2331-2334

45. Pace KE, Lee C, Stewart PL, Baum LG: Restricted receptor segregation into membrane microdomains occurs on human $T$ cells during apoptosis induced by galectin-1. J Immunol 1999, 163:3801-3811.

46. Walzel H, Schulz U, Neels P, Brock J: Galectin-1, a natural ligand for the receptor-type protein tyrosine phosphatase CD45. Immunol Lett 1999, 67:193-202.

47. Galvan M, Tsuboi S, Fukuda M, Baum LG: Expression of a specific glycosyltransferase enzyme regulates $T$ cell death mediated by galectin1. J Biol Chem 2000, 275:16730-16737.

48. Amano M, Galvan M, He J, Baum LG: The ST6Gal I sialyltransferase selectively modifies $\mathrm{N}$-glycans on $\mathrm{CD} 45$ to negatively regulate galectin1-induced CD45 clustering, phosphatase modulation, and T cell death. J Biol Chem 2003, 278:7469-7475. 
49. Imai $Y$, Matsushima $Y$, Sugimura T, Terada M: A simple and rapid method for generating a deletion by PCR. Nucleic Acids Res 1991, 19:2785.

50. Yang Z: A program package for phylogenetic analysis by maximum likelihood. Computer Appl Biosci 1997, 13:555-556.

51. Oda Y, Kasai K, Ishii S: Studies on the specific interaction of concanavalin A and saccharides by affinity chromatography. Application of quantitative affinity chromatography to a multivalent system. J Biochem 1981, 89:285-296.

52. Hirabayashi J, Hashidate T, Arata Y, Nishi N, Nakamura T, Hirashima M, Urashima T, Oka T, Futai M, Muller WEG, Yagi F, Kasai K: Oligosaccharide specificity of galectins: A search by frontal affinity chromatography. Biochim Biophys Acta 2002, 1572:232-254.

53. Hirabayashi J, Arata Y, Kasai K: Frontal affinity chromatography as a tool for elucidation of sugar recognition properties of lectins. Methods Enzymol 2003, 362:353-368.

54. Duan Y, Wu C, Chowdhury S, Lee MC, Xiong G, Zhang W, Yang R, Cieplak P, Luo R, Lee T, Caldwell J, Wang J, Kollman P: A Point-Charge Force Field for Molecular Mechanics Simulations of Proteins Based on CondensedPhase Quantum Mechanical Calculations. J Comput Chem 2003, 24:1999-2012.

55. Darden T, York D, Pedersen L: Particle mesh Ewald: An N.log $(\mathrm{N})$ method for Ewald sums in large systems. J Chem Phys 1993, 98:10089-10092

56. Ryckaert JP, Ciccotti G, Berendsen HJC: Numerical integration of the cartesian equations of motion of a system with constraints: molecular dynamics of n-alkanes. J Comput Phys 1977, 23:327-341.

57. Sugamura K, Fujii M, Kannagi M: Cell surface phenotypes and expression of viral antigens of various human cell lines carrying human T-cell leukemia virus. Int J Cancer 1984, 34:221-228.

58. Takeshita T, Goto Y, Tada K, Nagata K, Asao H, Sugamura K: Monoclonal antibody defining a molecule possibly identical to the p75 subunit of interleukin 2 receptor. J Exp Med 1989, 169:1323-1332.

doi:10.1186/1471-2148-10-43

Cite this article as: Konno et al:: Protein engineering of conger eel galectins by tracing of molecular evolution using probable ancestral mutants. BMC Evolutionary Biology 2010 10:43.

\section{Submit your next manuscript to BioMed Central and take full advantage of:}

- Convenient online submission

- Thorough peer review

- No space constraints or color figure charges

- Immediate publication on acceptance

- Inclusion in PubMed, CAS, Scopus and Google Scholar

- Research which is freely available for redistribution 